\title{
COMPARISON OF CONVENTIONAL AND ACOUSTIC IMPACT ECHO TESTS FOR DETECTING A CAVITY UNDERNEATH A CONCRETE SLAB TRACK
}

\author{
YUJIN LIM ${ }^{1}$, SEONGBAEK PARK ${ }^{2}$, HOJIN CHOI $^{3} \&$ JAEHAK PARK $^{3}$ \\ ${ }^{1}$ Department of Civil and Railroad Engineering, Paichai University, Korea \\ ${ }^{2}$ KORAIL Railroad Research Institute of Science and Technology, Korea \\ ${ }^{3}$ Global Solution Group, Korea
}

\begin{abstract}
Many types of unstable conditions of railway tracks including various modes of irregularities can be produced when cavities are generated exactly underneath a concrete slab track or a slight open space is made under a loose sleeper. The cavities can be generated due to various reasons such as settlements of badly compacted soil or soft soil or drastic change of track stiffness in transition zones near bridge abutment. The loose sleeper embedded in the concrete slab can also produce very undesirable problems including noise, vibration of track and unexpected response between railway car and track structure. Nonetheless, there are currently no useful and effective detecting methods for investigating the cavity presence underneath the railway concrete slab track and the loose sleeper embedded in the slab. In this study, a comparative study is performed for detecting the cavity and checking the condition of the loose sleeper by adapting conventional impact echo test and acoustic impact echo test on the concrete slab surface. It is confirmed that these two NDT methods can be discriminately adaptive techniques for detecting the problematic abnormalities in a concrete slab track. A test bed composed of a rectangular concrete slab with various sizes and height of cavity is built in the backyard for proof test. Detecting algorithm and processing program are developed and proposed based on wavelet and FFT of the obtained data. Acoustic impact echo test is proved to be effective and practical to detect a cavity underneath the concrete slab track. In addition, it is found that conventional impact echo test is also effective and useful to detect loose sleepers embedded in the concrete.
\end{abstract}

Keywords: cavity, acoustic impact echo test, slab track, NDT.

\section{INTRODUCTION}

Many types of unstable condition of railway track including various modes of irregularities can be produced when cavities are generated exactly underneath concrete slab track or a slight open space is made under a loose sleeper. The cavities can be generated due to various reasons such as settlements of badly compacted soil or soft soil and also drastic change of track stiffness in transition zone near bridge abutment (Fig. 1). The loose sleeper embedded in the concrete slab can also produce very undesirable problems including noise and vibration of track and unexpected response between railway car and track structure. Nonetheless, there are no useful and effective detecting methods at present for investigating the cavity presence underneath the railway concrete slab track and the loose sleeper embedded in the slab. In this study, a comparative study was performed for detecting the cavity and checking condition of the loose sleeper by adapting conventional impact echo test and acoustic impact echo test on the concrete slab surface. It is confirmed that these two NDT methods can be discriminately adaptive technique for detecting the problematic abnormalities in concrete slab track. A test bed consisting of rectangular concrete slab with various sizes and heights of cavity was built in the backyard for proof test. Detecting algorithm and processing program were developed and proposed based on wavelet and FFT of the obtained data. In addition, another type of concrete slab was built in the field for comparison purpose that has various shapes, depths and sizes of cavity underneath the slab. 


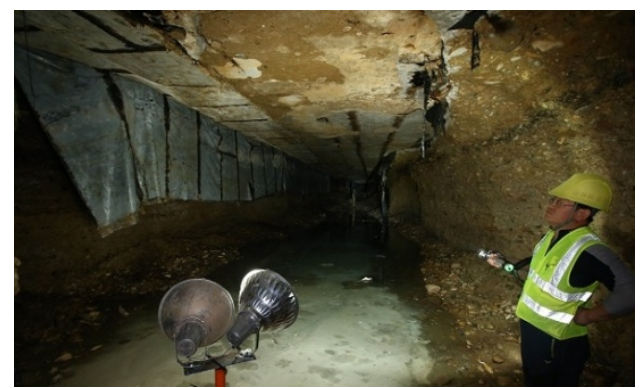

(a)

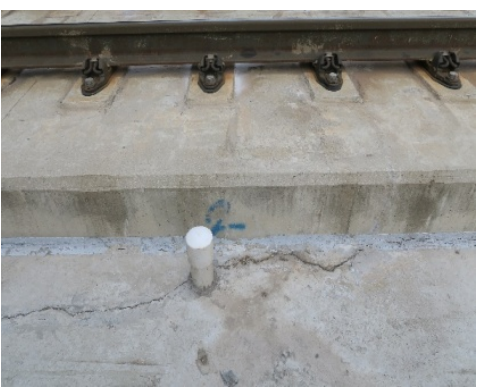

(b)

Figure 1: Railway track with abnormalities. (a) Large cavity generation below subway track; (b) A possible railway track with a gap.

In this study, acoustic impact echo test is proved to be effective and practical to detect cavity underneath the concrete slab track. In addition, it is found that conventional impact echo test is also effective and useful to detect loosely embedded sleeper or gaps in the concrete slab.

However, NDT method based on elastic stress wave can detect defects in the concrete structure using sensors instrumented directly on the surface of the structure to get propagated elastic stress waves. These NDT methods have been used to measure the slab thickness [1], [2] or identify location (depth) and size of the defects in the structure, and also to monitor strength of the concrete structure [3], [4]. Recently, many NDT methods based on acoustic waves have been developed. Especially, sensing methods to investigate layered structure based on leaky Rayleigh acoustic elastic waves are newly developed in NDT area, and are improved quite a lot. Acoustic impact echo test, one of NDT method based on leaky Rayleigh acoustic wave is non-contacting method since it uses microphone to catch leaky Rayleigh acoustic waves in the air above the structure.

In advance, before performing this study, a broad finite element analysis was performed for clarifying the effectiveness of using NDT-RAW method in order to check whether the acoustic impact echo test with a microphone be used to detect cavity or void existing below concrete slab of railway track [5]. In previous study of FEA, it was pointed out that the acoustic impact echo test be very effective to find out gap existence below the track slab.

\section{CAVITY EXISTENCE UNDER TRACK SLAB}

Many concrete structures are built for wide purposes such as railway slab track, PCC pavement, bridge slab, columns and pipes etc. However, old concrete structures have possibilities of having damages such as cracks and defects in themselves so that it is urgently required to investigate conditions of the old structures holding the damages and defects before repairing or reconstruction. In special, the railway concrete slab track has experience harsh environment during service time after construction due to repeated heavy wheel loading and severe temperature variation daily and seasonally. Recently, the authorities of railway have interest in technologies to detect cavities or gaps underneath the railway concrete slab track since water leaks from old and damaged utility pipes and flows into surrounding soils that can cause generation of cavities. All defects and damages including gaps generated in the railway concrete slab track may decrease design life of the slab track.

In case of concrete slab track, number of construction sites has been steadily increased since the opening of the second line of the Gyeongbu Highspeed Railway in 2010 in Korea. 


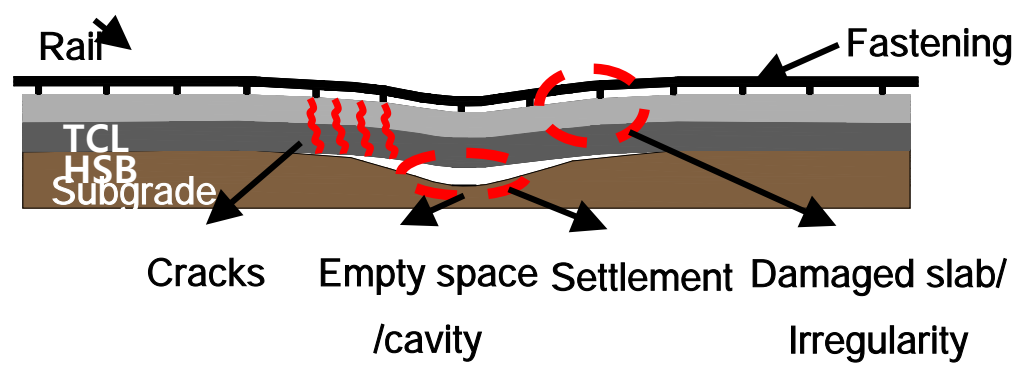

Figure 2: Schematic of railway track slab with cavity or gap.

Even though it has many advantages in view of maintenance and track safety that can overcome even the disadvantages of high initial construction costs, unlike the initial healthy concrete track condition, many defects have been found and reported recently. Therefore, it is necessary to develop a new detection system capable of checking the defects and of evaluation process of trackbed condition based on new NDT system. In this study, we investigated the plausibility of adapting NDT system capable of quickly investigating conditions of unstable track structures such as track slab with cavity under or at the interface of the bottom of TCL/HSB layer by using classical and acoustic impact echo tests.

Most of all NDT techniques available at this time are based on sensors that should be lied or attached on and fully be contacted with the surface of the structure to be tested in order to obtain reasonable and reliable test data. This means that the surface condition can be a critical factor for the classical NDT techniques. Rough surface of the railway track slab imposes difficult problems to the NDT tester. It takes a lot of time for the NDT tester to prepare the concrete surface to be clean and smooth by grinding and polishing to get reliable data. An alternative technique is to adapt non-contact NDT method that excludes physical contacting surface between the sensor and the structure to be tested from the test in order to get good and reliable data collection and data processing.

However, it is not easy for the non-contacting NDT methods to display the location and size of defects in or below railway track slab as processed clearly defined images to be distinguished from surrounding materials.

In this study, several model concrete slabs were constructed in a backyard test area. The slabs were simulated as railway track slab with gaps in the body itself or cavities between the slab and the track soil foundation. The locations and depths of the cavities and gaps in the model concrete slab were inspected by adapting the so-called classical and the acoustic impact echo tests and by investigating the frequency response of the elastic waves generated in the slab.

In this study, a Short-time Fourier Transform (STFT) technique was adapted for timefrequency analysis. A schematic overview of testing and performing STFT using the obtained test data is demonstrated in Fig. 3. In-detail procedures about performing STFT to get wavelet forms and Auto Spectrum Density were explained by Cho et al. [5], [6].

\subsection{Construction of model slab simulating railway track with cavity}

Small concrete slabs were constructed in a backyard test site for simulating railway track slab that had a gap between TCL (track concrete layer) and HSB (hydraulically stabilized base) 


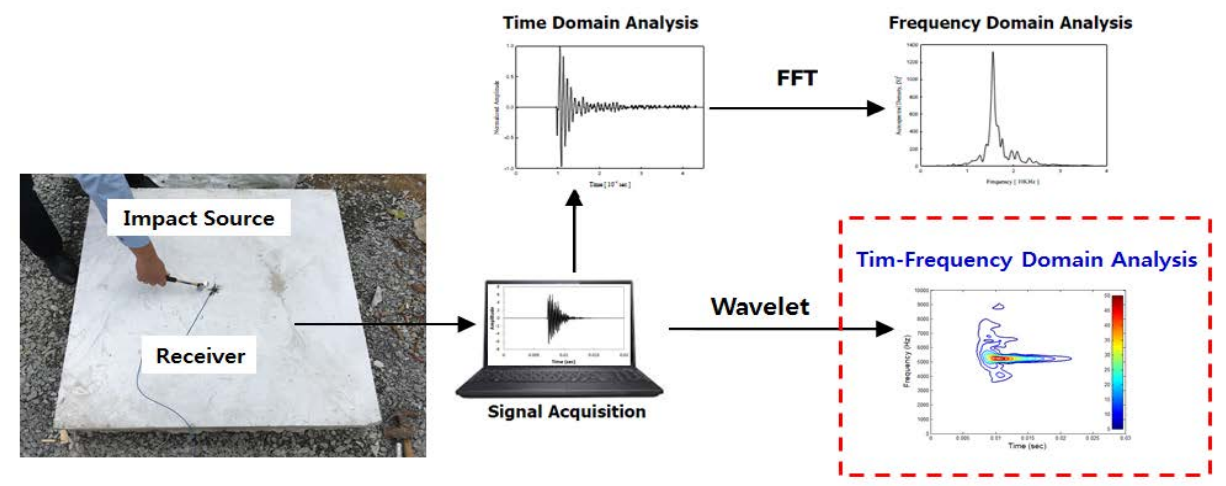

Figure 3: Overview of time-frequency analysis method.

layer of the track (Fig. 4). The so-called classical impact echo test and the acoustic impact echo test were performed on the slab independently. Various sizes of the gap were simulated. The slabs were square type and were $100 \mathrm{~cm}$ wide and $10 \mathrm{~cm}$ high. The gaps were simulated by inserting a rectangular Styrofoam hard board that was $10 \mathrm{~cm}$ wide and $1 \mathrm{~cm}$ tall. The Styrofoam boards were inserted at depths of 5,10 and $15 \mathrm{~cm}$ respectively from top of the slab surface for simulating the gap locations. Another model concrete slab was prepared in the same backyard test site for comparison purpose of simulating the railway track slab with cavity generated between the slab and the soil foundation.

Most of all, it is primary interest of performing the impact echo tests on the model slab to investigate change or difference of resonance frequency for the slab with and without gap. If it is not enough to distinguish the slab with gap from the sound slab based on the frequency difference, it should be notified that the frequency characteristics only be not verifier for gap existence in the slab.

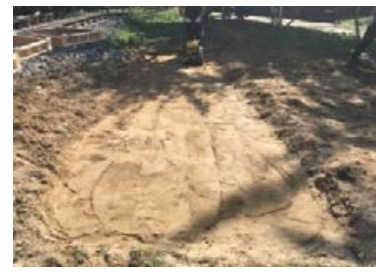

(a)

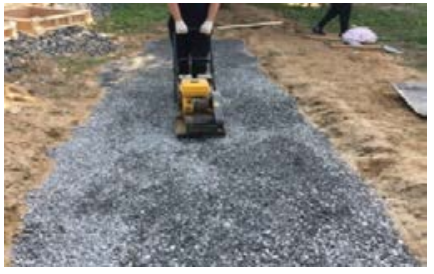

(b)

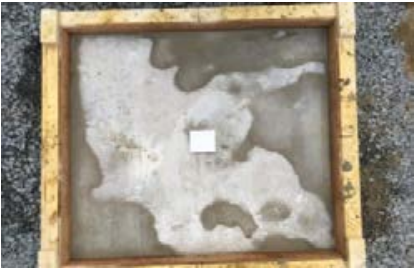

(c)

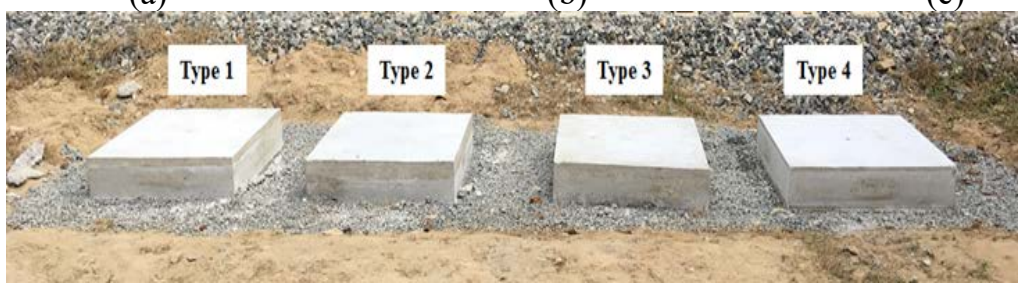

(d)

Figure 4: Construction process of model concrete slabs with and without gap at interface of TCL and HSB. (a) Foundation compaction; (b) Pouring crushed stones and compaction; (c) Insertion of Styrofoam board; (d) Concrete slabs constructed. 
In addition, another type of concrete slab was built in the field for comparison purpose that has various shapes, depths and sizes of cavity underneath the slab.

\subsection{Test system setup}

Newly designed acoustic impact echo test system was setup as shown in Fig. 5. Two high performance microphones were used for getting transmitted leaky Rayleigh waves into air from the surface of the slab. Table 1 explains major specifications of test system adapted for testing. A small steel hammer was adapted for applying impact force on the slab to generate stress wave. An accelerometer was installed also on the top surface of the model slab. MATLAB program was used and coded to perform STFT analysis and also to convert the obtained wave data to wavelet forms.

\section{TEST RESULTS AND STFT WAVELETS}

\subsection{Classical impact echo test}

Fig. 6 illustrates typical results of the impact echo test applied to the model slab with and without gap in the slab at various depths. When a Styrofoam board simulated as a gap in slab

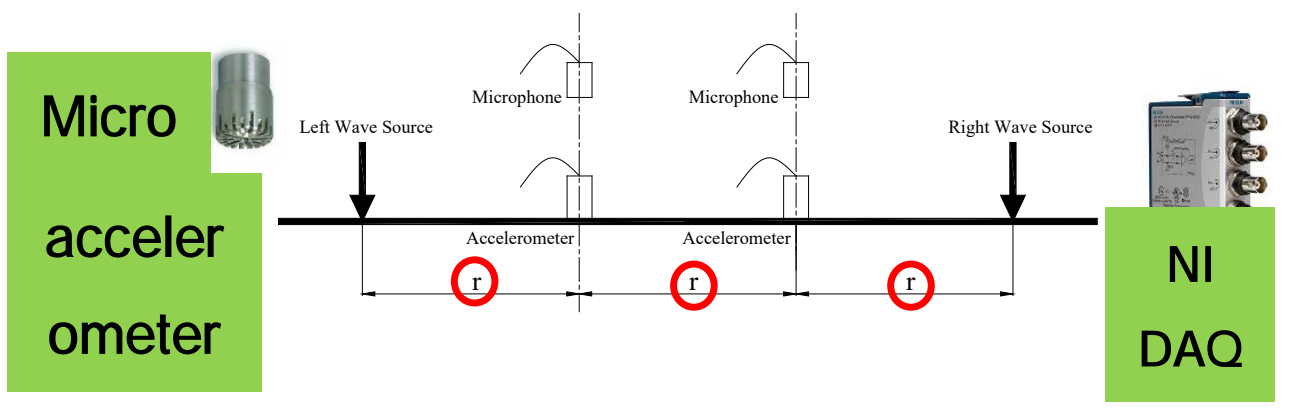

Figure 5: Schematic of acoustic impact echo test system.

Table 1: Test system specification

\begin{tabular}{|c|c|c|}
\hline Equipment & \multicolumn{2}{|c|}{ Specification } \\
\hline \multirow{3}{*}{$\begin{array}{l}\text { Accelerometer } \\
\text { (PCB352C22) }\end{array}$} & Resol. (g rms) & 0.002 \\
\hline & Freq. (Hz) & $1.0 \sim 10,000$ \\
\hline & Sensitivity $(\mathrm{mV} / \mathrm{g})$ & 10 \\
\hline Impact hammer & Hammer & Steel \\
\hline \multirow{2}{*}{ DAQ system (NI) } & Max samp. $\operatorname{rate}(\mathrm{kS} / \mathrm{s})$ & 51.2 \\
\hline & Reference voltage(V) & \pm 5 \\
\hline $\begin{array}{l}\text { Signal conditioner } \\
\text { (PCB482A16) }\end{array}$ & Frequency range $(\mathrm{Hz})$ & $0.15-100,000$ \\
\hline
\end{tabular}



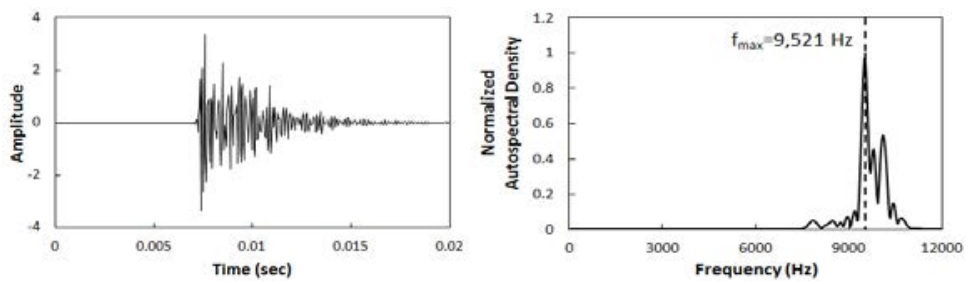

(a)
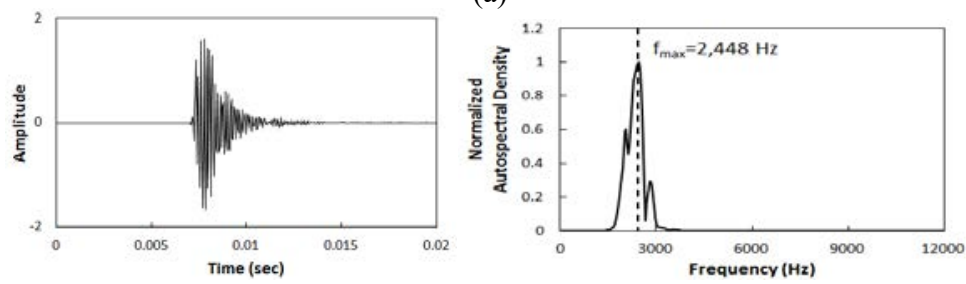

(b)

Figure 6: Classical impact echo test results for model concrete slab with different cavity depth. (a) Depth: 5cm; (b) Depth: $20 \mathrm{~cm}$.

was placed at shallower depth, it was clearly seen that the resonance frequency is higher than those of the slab with deeper gap. And also if shape factor $\beta$ as introduced by Sansalone and Streett [4] is 0.96 , the depth locations where the board inserted in the slab were easily detected by the classical impact echo test.

Fig. 7 illustrates acceleration wavelets in time-frequency plane obtained by STFT of the data from classical impact echo test. It would be concluded temporarily for all the slabs with gap that most wavelet forms were extended longitudinally to direction of the time axis with relatively longer time. Spectrum density values were also much higher in the slab with gap than the slab without gap. On the other hand, the slab without gap provided wavelet forms to be extended vertically, i.e. to direction of the frequency axis with relatively shorter time duration. Spectrum density values were also relatively smaller in the slab without the gap than the slab with the gap.

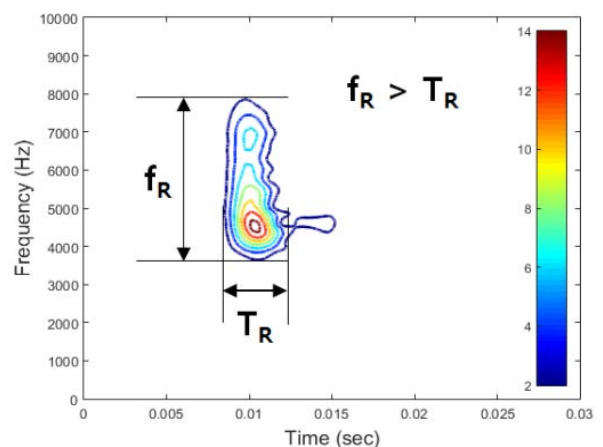

(a)

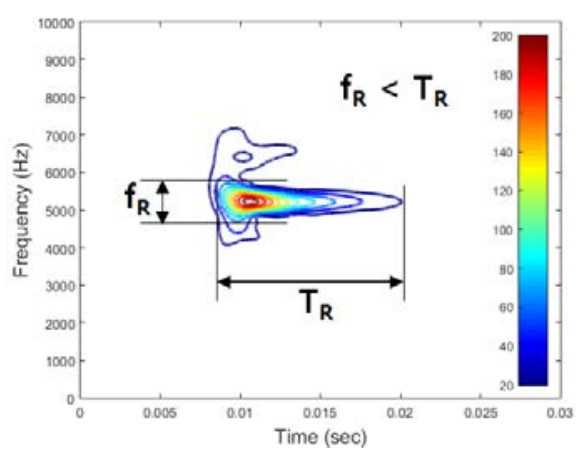

(b)

Figure 7: Wavelet contour shapes in cases of with cavity or without cavity existence underneath slab obtained from classical impact echo test. (a) Wavelet contour of without cavity case; (b) Wavelet contour of with cavity case. 


\subsection{Acoustic impact echo test}

As described, another type concrete slab was built in the filed for comparison purpose with various depths and sizes of cavity underneath the slab. A typical acoustic impact echo test results including wavelets and auto-spectrum density were demonstrated in Fig. 8 with schematic of railway track slab with and without cavity.

Where there was a cavity underneath the railway track slab as shown in the figure, it could be temporarily decided that typical wavelet contours were shaped as pistol with a trigger and extended longitudinally like a gun barrel in parallel direction with time axis. For the trigger position as shown in the figure, it could be notified that some amount of waves were reflected at the bottom of the cavity and clearly some waves were reflected at the bottom of the slab. Naturally, remnant waves were transmitted into deep soil ground below the cavity.

\section{CONCLUDING REMARKS}

In this study, a test bed composed of rectangular concrete slab with various sizes and height of cavity was built in a backyard test bed for performing classical and acoustic impact echo tests to check whether the NDT test methods can be used for detecting cavity or gap in the track slab. Detecting algorithm and processing program were developed and proposed based on wavelets and STFT of the obtained data.

Acoustic impact echo test was proved to be effective and practical to detect cavity underneath the concrete slab track. In addition, it was found that conventional impact echo test was also effective and useful to detect a gap in the concrete. Both the impact echo test
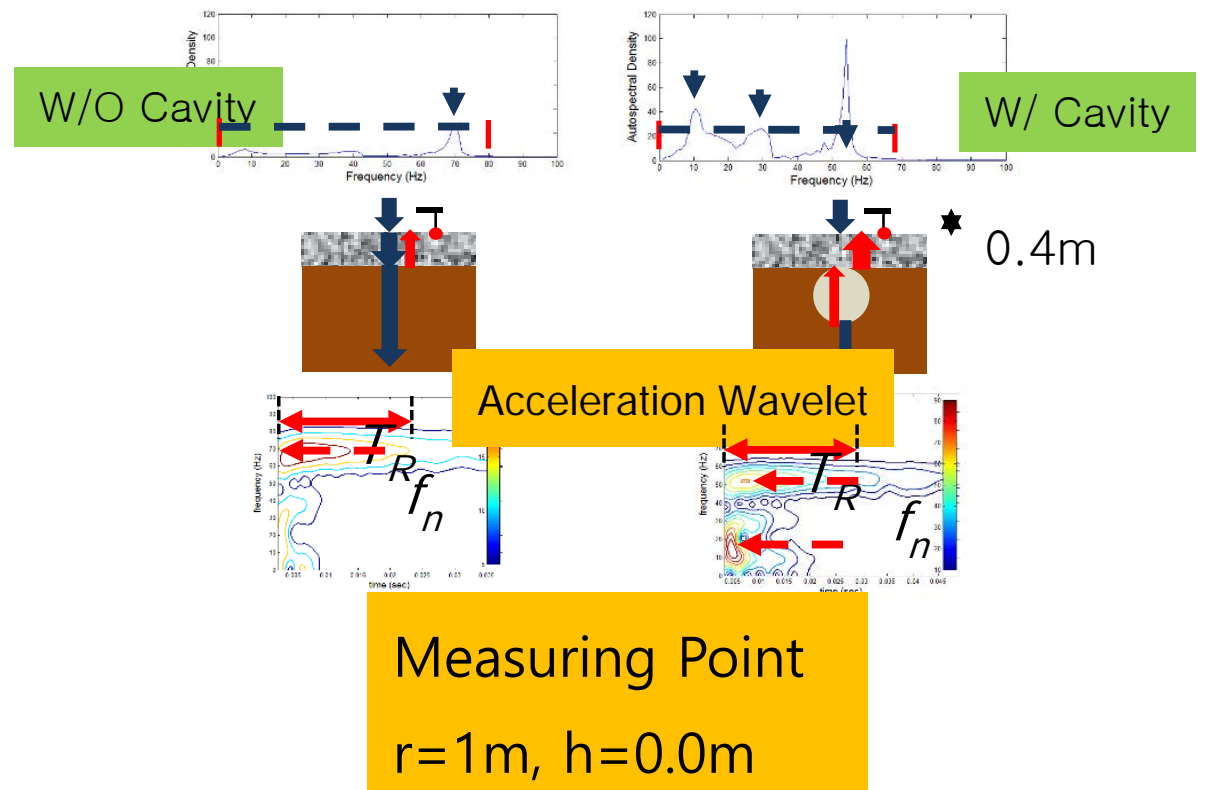

(a)

(b)

Figure 8: Acoustic impact echo test results and schematic of railway track slab. (a) Slab without cavity; (b) Slab with cavity. 
methods with wavelet transform method (STFT) can be used to detect abnormalities in the track slab because it can provide better judgment criteria than the methods with using the conventional frequency analysis method.

\section{ACKNOWLEDGEMENT}

This research was supported by a grant no. 18RTRP-B113566-03 from Railroad Technology Research Program funded by Ministry of Land, Infrastructure and Transport of Korean government.

\section{REFERENCES}

[1] Sansalone, M. \& Carino, N.J., Impact-Echo: A Method for Flaw Detection in Concrete Using Transient Stress Waves, National Bureau of Standards: Springfield, pp. 21-31, 1986.

[2] Sansalone, M., Impact-echo: the complete story. ACI Structural Journal, 94(6), pp. 777786, 1997.

[3] Carino, N.J., Training: often the missing link in using NDT methods. Construction and Building Materials, 38(1), pp. 1316-1329, 2013.

[4] Sansalone, M. \& Streett, W.B., Impact-Echo: Nondestructive Testing of Concrete and Masonry, Bullbrier Press: Jersey Shore, pp. 9-13, 1997.

[5] Cho, H., Lee, J.W., Lee, S.J. \& Lim, Y., A detecting method for cavity below concrete slab track based on SASW technique using leaky Rayleigh acoustic wave in air. Proceedings of the 14th International Conference on Railway Engineering, Edinburgh, 2017.

[6] Cho, H., Park, S.B., Park, J.H., Kwon, S.G. \& Lim, Y., Inspection of gaps and abnormalities of concrete slab in railway track by using wavelet transform analysis and impact echo test. Journal of the Korean Society for Railway, 20(6), pp. 795-808, 2017. 